Institute of $\mathbf{F}_{\text {ood and }} \mathbf{A}_{\text {gricultural }} \mathbf{S}_{\text {ciences }}$

\title{
Manual de los Reglamentos del Agua de Florida: Apéndice ${ }^{1}$
}

Michael T. Olexa, Laura Minton, Dulcy Miller, y Sarah Corbett ${ }^{2}$

\section{Agradecimientos}

Los autores agradecen a Richard Budell de la Oficina de Política del Agua Agrícola del Departamento de Agricultura y Servicios al Consumidor de Florida. Los autores también agradecen a David H. Hammonds, Consultor del Programa de Salud Ambiental, Oficina de Programas de Aguas de Drenaje en el Sitio, del Departamento de Salud de Florida, y a Edward A. Bettinger, Consultor del Programa de Salud Ambiental, Oficina de Programas de Agua del Departamento de Salud de Florida.

\section{Lista de Acrónimos}

- PMM - Practicas del Mejor Manejo

- ARCRAC - Acta de Responsabilidad, Compensación y Respuesta Ambiental Completa (o Superfondo)

- AAL - Acta del Agua Limpia

- DASC - Departamento de Agricultura y Servicio al Consumidor

- DPA - Departamento de Protección

Ambiental

- DS - Departamento de Salud

1. Este es el documento EDIS FE089, una publicación del Department of Food and Resource Economics, Florida Cooperative Extension Service, Institute of Food and Agricultural Sciences, University of Florida, Gainesville, FL. Publicada Noviembre 2002. Por favor visite la página electrónica EDIS en http://edis.ifas.ufl.edu.

2. Michael T. Olexa, es profesor del Department of Food and Resource Economics, Florida Cooperative Extension Service, Institute of Food and Agricultural Sciences, University of Florida, Gainesville, FL; y miembro de Florida Bar; Presidente de Agricultural Law Committee of The Florida Bar; y Director del Agricultural Law Center. Laura Minton, Dulcy Miller, y Sarah Corbett son estudiantes graduadas de Levin College of Law, University of Florida, Gainesville, FL. Filiberto Reyes-Villanueva fue el traductor de la versión en ingles al español.

Esta publicación esta diseñada para proporcionar información precisa, actualizada y autorizada sobre esta material. Sin embargo, ya que las leyes, reglas administrativas y decisiones de la corte, sobre las cuales están basados, están sujetas a revisión constante; algunas partes de esta publicación podrían ser obsoletas en cualquier momento. Esta publicación es distribuida bajo el entendimiento que los autores no están involucrados en ninguna representación legal u otros servicios profesionales, y que la información contenida aquí no debe ser considerada como un substituto de una asesoria legal. Esta publicación no esta completa en proporcionar toda la información para lograr el cumplimiento de las leyes y reglamentos que gobiernan la protección del agua. Por estas razones, el uso de estos manuales por cualquier persona constituye un acuerdo para mantener libre de daño a los autores, al Florida Cooperative Extension Service, al Institute of Food and Agricultural Sciences, y a la University of Florida por cualquier demanda por responsabilidad de daños, o gastos en que pueda incurrir cualquier persona, como un resultado de hacer referencia o confianza sobre la información contenida en esta publicación. Esta publicación fue apoyada financieramente por el Florida Department of Agriculture and Consumer Services.

El Instituto de Alimentos y Ciencias Agrícolas es Un empleador que opera bajo Acción Afirmativa y provee Oportunidades Igualitarias, dedicado a promocionar la investigación, a información educativa y otros servicios, únicamente a los individuos e instituciones que operan baj discriminación sin considerar color, raza, sexo, edad, incapacidad u origen. Para más información sobre como obtener otras publicaciones de la extensión, comuníquese con la oficina de Servicio de Extensión de su condado. Servicio de Extensión de la Florida / Instituto de Alimentos y Ciencias Agrícolas / Universidad de la Florida / Christine Taylor Waddill, Decana. 
- APA - Agencia de Protección Ambiental

- AEPE - Acta de Especies en Peligro de Extinción

- CAF - Código Administrativo de Florida

- AFIFR - Acta Federal de Insecticidas, Fungicidas y Rodenticidas

- AFCCA - Acta Federal para el Control de Contaminación de Aguas

- APCA - Acta de Protección de Calidad Alimentos

- CCPAD - Comisión de Caza y Pesca de Agua Dulce

- MAAS - Manejo y Almacén de Aguas Superficiales

- ANPA - Acta Nacional de la Política Ambiental

- INSSO - Instituto Nacional para Salud y Seguridad Ocupacional

- SNEDC - Sistema Nacional de Eliminación de Descargas Contaminantes

- ARCR - Acta para la Recuperación y Conservación de Recursos

- SCS - Servicio para la Conservación del Suelo

- AAPS - Acta del Agua Potable Segura

- DMASF - Distrito de Manejo de Agua del Sur de Florida

- GCP - Generador de Cantidades Pequeñas

- DCSA - Distrito de Conservación del Suelo y Agua

- MMAS - Manejo y Mejoramiento de Aguas Superficiales

- ACST - Acta de Control de Sustancias Toxicas
- CIAS - Control de Inyección de Aguas Subterráneas

- DAEU - Departamento de Agricultura de los Estados Unidos

- DMA - Distrito de Manejo de Agua

- SPAD - Sección de Protección de Aguas

Divisorias 